\title{
Viscoelastic characterization and comparison of Norwegian asphalt mixtures using dynamic modulus and IDT tests
}

\author{
M. Alamnie \& E. Taddesse \\ Department of Civil and Structural Engineering, University of Agder (UiA), Grimstad, Norway \\ I. Hoff \\ Department of Civil and Transport Engineering, Norwegian University of Science and Technology, Trond- \\ heim, Norway
}

\begin{abstract}
This paper presents the comparison of stiffnesses of two types of asphalt concrete mixes (Ab11 and Agb11) fabricated in the laboratory using two commonly used stiffness tests. (1) uniaxial compression dynamic modulus ( $\left.E^{*}\right)$ and (2) Indirect tensile resilient modulus (Mr) tests are conducted at various temperatures, frequencies, and loading times. As expected, both $\mathrm{E}^{*}$ and $\mathrm{Mr}$ values decrease as temperature increases and frequency decreases. It is observed that the $\mathrm{Mr}$ is generally less than the $\mathrm{E}^{*}$. However, this phenomenon is dependent on frequency, temperature, and material type. The viscoelastic property of the two mixes is characterized using the time-temperature superposition principle. Master curves are developed using the mathematical sigmoid and the rheological 2S2P1D models. It has been observed that the rheological model has shown difficulty to converge optimization error to fit $\mathrm{Mr}$ master curve while sigmoid function accurately fitted the measured data. $\mathrm{Mr}$ is compared with $\mathrm{E}^{*}$ both in frequency and time domains using master curves. A closer comparison is observed with the storage modulus( $\left(E^{\prime}\right)$ and time-domain relaxation modulus $E(t)$ master curves. Considering the inherent time-domain property of $\mathrm{Mr}$, it is recommended to compare with $\mathrm{E}^{\prime}$ or $\mathrm{E}(\mathrm{t})$. From the master curves and data analysis and by considering inputs such as energy loss, modular ratio, frequency, temperature, and other volumetric properties, a rigorous $\mathrm{Mr}$ vertical shifting function can be developed. Finally, a material database is obtained for Norwegian asphalt mixes.
\end{abstract}

Keywords: Viscoelastic, Dynamic Modulus, Resilient Modulus, 2S2P1D Model

\section{INTRODUCTION}

Asphalt concrete (mixture) is a composite material constituted of aggregate particles embedded in a bitumen/binder. The asphalt binder firmly adheres to the aggregate particles and binds them to form asphalt concrete (a.k.a. bituminous mixture). Asphalt concrete is a viscoelastic material at small strain or stress levels, whereas it behaves in a nonlinear viscoelastoplastic manner at high temperatures and large deformations. Since the pioneering of the mechanistic-based design method, enormous research efforts are put forth towards developing more accurate and complicated testing methods. Various field and laboratory test methods are developed to characterize asphalt concrete in linear, nonlinear, viscoelastic, or viscoplastic states. A wide range of material data is needed to calibrate advanced pavement design models, which required extensive testing using advanced test equipment. However, equipment cost, 
complexity equipment/test method, and requirements skilled labor/time are imminent challenges.

For this reason, asphalt material characterization still relies on simple performance indicators such as Indirect tensile, Marshall stability, and other rheological tests. The Indirect Tensile (IDT) resilient modulus test is a standard test used as a performance indicator to assess stiffness, permanent deformation, and fatigue cracking of asphalt concrete (Bennert et al., 2018). The small strain dynamic modulus test is another well-known test for linear viscoelastic characterization of asphalt concrete in the frequency domain. In essence, the IDT strength is a relative indicator of the resistance of the asphalt mixture to tensile loads. Efforts have been made to correlate the IDT resilient modulus and dynamic modulus values (Lacroix et al., 2007, Ping and Xiao, 2008, Loulizi et al., 2006).

This study aims to characterize and compare dynamic modulus and IDT resilient modulus tests using two laboratory fabricated asphalt concrete mixtures used in Norway. For the test campaign, the small strain (viscoelastic) range is considered for both test methods. The asphalt mixtures are selected based on binder stiffness (i.e., soft and relatively harder polymermodified binder mixes). Moreover, the study investigates the correlation between $\mathrm{E}^{*}$ and $\mathrm{Mr}$, and $\mathrm{Mr}$ with storage dynamic modulus $\left(\mathrm{E}^{\prime}\right)$ using the superposition principle and through the use of master curves. In addition, a material database is obtained for the Norwegian asphalt concrete mixes.

\section{THEORETICAL BACKGROUND}

The performance of asphalt concrete is dependent on the fundamental thermodynamic variables (temperature and pressure) and loading frequency. The effect of temperature has been studied with more emphasis than pressure. The superposition principle of Time and Temperature (TTSP) is used to develop viscoelastic models. Several researchers have validated the applicability of TTSP for asphalt concrete with and without damage (i.e., in linear or small strain, and nonlinear or large strain states) (Schwartz et al., 2002, Zhao and Richard Kim, 2003, Yun et al., 2010, Nguyen et al., 2013). The TTPS is used to shift experimental data (at various temperatures, stress, frequency, strain rate, etc.) to a specified reference parameter (such as temperature, stress, or strain rate). A material that satisfies the superposition principle is called a thermo-rheologically simple material. Using TTSP, the same material response can be obtained either at low temperatures and longer loading times (low frequency) or at high temperatures but short loading times (high frequency). The relationship can be described as follows (Equation 1).

$$
|\mathrm{E} *(\mathrm{~T}, \mathrm{f})|=\left|\mathrm{E} *\left(\mathrm{f}_{\mathrm{R}}\right)\right|
$$

Where, $f_{R}=f \quad a T=$ reduced frequency; $\mathrm{f}=$ frequency; $a T=$ shift factor for temperature $(\mathrm{T})$.

The horizontal shifting behavior allows for the processed data to form a single curve but with a wide frequency beyond the experimental window. The curve generated by shifting experimental data is called the master curve. The Time-temperature shift factor (amount of horizontal shift to a reference temperature) and the master curve enable us to predict the linear viscoelastic (LVE) behavior over a wide range of time, frequency, stress, strain, etc. Different shift factor models are available in the literature (Yusoff et al., 2011). The Williams, Landel, and Ferry (WLF) function (Williams et al., 1955) is the commonly used model (Equation 2).

$$
\log \left(a_{T}\right)=-\frac{C_{1}\left(T-T_{r}\right)}{\left(T-T_{r}\right)+C_{2}}
$$

Where $C_{1}, C_{2}-W L F$ constants 


\section{EXPERIMENTAL PROGRAM}

\subsection{Materials and sample production}

In this study, two widely used asphalt mixtures in Norway (identified as Ab11, Agb11) are used for investigation. The mixes are collected from a production plant supplied by an asphalt producer. Both mixes have a nominal maximum aggregate size (NMAS) of $11 \mathrm{~mm}$, as shown in the granulometric distribution (Table 1). The Ab11 is a polymer-modified mix (70/100 binder grade and $5.6 \%$ content), and it is mainly used in high-traffic pavement. On the other hand, the Agb11 is a soft mixture mainly applied for low to medium-traffic roads and contains $5.83 \%$ content of a $160 / 220$ grade type binder. The sampled mix is reheated at $150^{\circ} \mathrm{C}$ for 4 hours before compaction in a gyratory compactor. The $150 \mathrm{~mm}$ diameter and $180 \mathrm{~mm}$ height cylindrical samples are cored and cut to get the final specimens for dynamic modulus $(100 \mathrm{~mm}$ $150 \mathrm{~mm}$ height) and resilient modulus (100 $\mathrm{mm} \quad 45$ to $50 \mathrm{~mm}$ thickness).

Table 1. Aggregate gradation (Ab11 and Agb11).

\begin{tabular}{lll}
\hline & \multicolumn{2}{l}{$\%$ Passing } \\
\cline { 2 - 3 } Sieve Size (mm) & Agb11 & Ab11 \\
\hline 16 & 100 & 100 \\
11.2 & 95 & 95 \\
8 & 77 & 70 \\
4 & 56 & 48 \\
2 & 41.5 & 36 \\
1 & 31.5 & 27.5 \\
0.25 & 15 & 15.5 \\
0.063 & 7.5 & 10 \\
\hline
\end{tabular}

\subsection{Mechanical characterization of asphalt concrete}

In the dynamic modulus ( $\left.E^{*}\right)$ test, a uniaxial compressive sinusoidal (harmonic) load is applied on a specimen without a rest period (no delayed elastic rebound) at different frequency sweeps (Figure $1 \mathrm{a}$ ). The steady-state stress is applied so that it maintains an axial strain amplitude $\left(\varepsilon_{o}\right)$ between 50 to $100 \mu \mathrm{m} / \mathrm{m}$ and smaller (Gayte et al., 2016, Schwartz et al., 2002). A strain amplitude up to $150 \mu \mathrm{m} / \mathrm{m}$ is recommended in compression (Levenberg and Uzan, 2004). However, the idealized steady-state (harmonic) condition is deviated due to transient behaviors, such as non-uniform loading, nonlinearity, or any other phenomenon (Gayte et al., 2016). A complex number (E ) defines the stress-strain relationship under continuous sinusoidal loading. The theoretical sinusoidal evolutions of the three measured parameters with time (strain, stress, and dynamic modulus) are expressed in Equations 3 to 5.

$$
\begin{gathered}
\varepsilon(\mathrm{t})=\varepsilon_{\mathrm{o}} \sin (\omega \mathrm{t}) \\
\sigma(t)=\sigma_{o} \sin (\omega t+\varphi) \\
E^{*}=\frac{\sigma_{o}}{\varepsilon_{o}} e^{j \varphi}=\left|E^{*}\right|(\cos \varphi+i \sin \varphi)=\left|E^{*}\right| e^{j \varphi}
\end{gathered}
$$

Where, $\left|\mathrm{E}^{*}\right|=\mathrm{E}^{\prime}+i \mathrm{E}^{\prime \prime}, \mathrm{E}^{\prime}=|E *| \cos \varphi-$ storage modulus and $\mathrm{E}^{\prime \prime}=|\mathrm{E}| \sin \varphi-$ loss modulus; $\varepsilon_{\mathrm{o}}, \sigma_{\mathrm{o}}-$ the axial strain and stress amplitudes, respectively; $i$ - complex number $\left(\mathrm{i}^{2}=-1\right) ; \varphi-$ phase angle $\left[0,90^{\circ}\right]$ which is calculated using time lag $\left(t_{l}\right)$ in strain signal and loading period $\left(t_{p}\right)$ of the stress signal (i.e., $\left.\varphi=360^{\circ} \quad \frac{t_{l}}{t_{p}}\right)$. 
On the other hand, in the resilient modulus (Mr) test, a haversine compressive load is usually applied with a rest period along the vertical diametral plane of a cylindrical asphalt concrete specimen (Figure $1 \mathrm{~b}$ ). The load should be selected to avoid damage to the sample at different pulse and rest periods. A minimum of $200 \mathrm{~N}$ axial force and 50 microstrains target deformation are selected. The $\mathrm{Mr}$ is calculated using the measured recoverable strain (deformation) during the unloading and the rest period with an assumed constant Poisson ratio, $\mu=0.35$ (EN 12697-26). It should be noted that the haversine load with a rest period can be decomposed into a cycle of true sinusoidal load and a creep load.

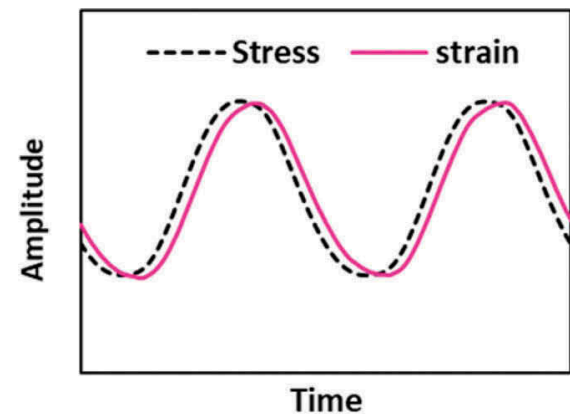

Time (a)

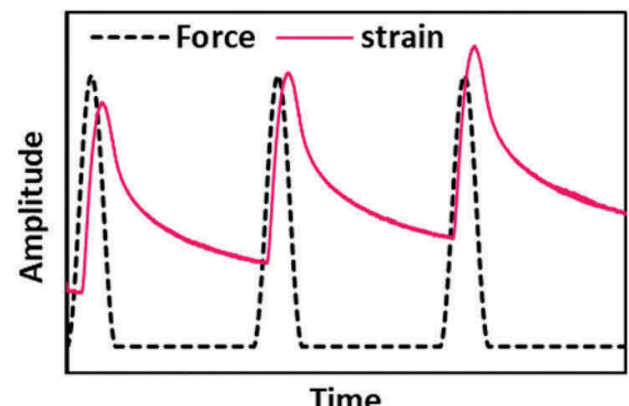

Time (b)

Figure 1. Stress-strain signal responses (not to scale) (a) Dynamic Modulus (b) Resilient Modulus.

Three sets of linear variable differential transducers (LVDTs) are mounted at 120 degrees apart for the dynamic modulus test, while two flat end LVDTs are used for the resilient modulus test. The instrumented specimen is conditioned at target temperature (at least two hours) in a separate chamber and then installed for testing in a UTM-130 machine with a temperature chamber. A dummy sample is used to control the surface and core temperature of a sample.

\section{TEST RESULTS}

The dynamic modulus test is conducted at three target temperatures $\left(5,21,40{ }^{\circ} \mathrm{C}\right)$ and seven frequencies $(10,5,2,1,0.5,0.2,0.1 \mathrm{~Hz})$ on two asphalt mixtures (Ab11 and Agb11). Similarly, the resilient modulus test is conducted at five temperatures $\left(5,10,21,30\right.$, and $\left.40{ }^{\circ} \mathrm{C}\right)$ and different loading times. The loading times are selected to match the frequency used for the dynamic modulus test. The dynamic and resilient moduli test results are shown in Figure 2 and Figure 3. As expected, both dynamic and resilient moduli decrease as temperature increases and frequency reduced. It is important to note that the Mr value is highly dependent on the magnitude of the applied load and selected loading time. Hence, the pulse load is selected based on the estimated stiffness at target temperature and frequency. In this study, ten conditioning cycles are applied at each frequency, and the last five load pulses are used to estimate the $\mathrm{Mr}$ value. A tuning test is conducted to estimate the initial modulus for dynamic modulus at each test temperature. The coefficient of variance $(\% \mathrm{CV})$ for the last five loading pulses is generally less than $10 \%$ in all measurements at different loading times and temperatures.

To compare $\mathrm{E}^{*}$ and the $\mathrm{Mr}$, the loading time or frequency should be equivalent in both tests (i.e., $\omega=1 / \mathrm{t}$ or $f=1 / 2 \pi t$ ). The ratio of $\mathrm{E}^{*}$ to $\mathrm{Mr}$ is computed (i.e., $E=\kappa \quad M r$ where $\kappa$ is a ratio) at the same frequency and temperature. The average $\kappa$ values are 1.27 and 1.12 for Ab11 and Agb11 asphalt concrete mixtures, respectively. As shown in Figure 4, the ratio $(\kappa)$ is 
dependent on temperature, frequency, and asphalt type. It is observed that $\kappa$ increases as temperature and frequency increase.

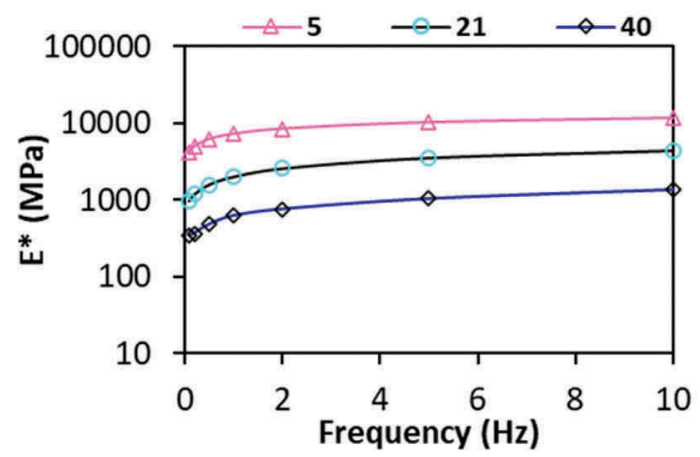

(a)

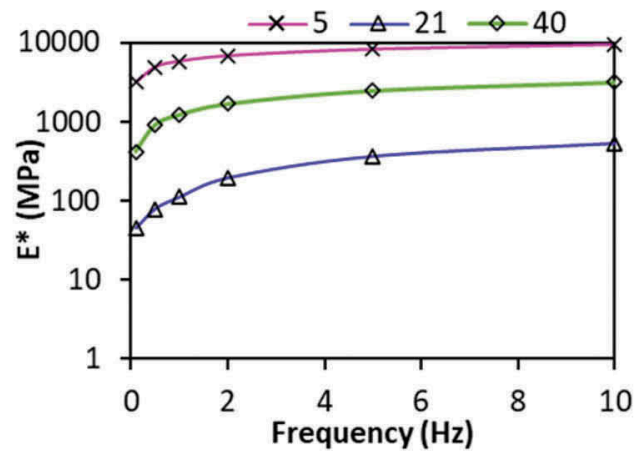

(b)

Figure 2. Dynamic Modulus (E*) test results (a) Ab11 (b) Agb11.

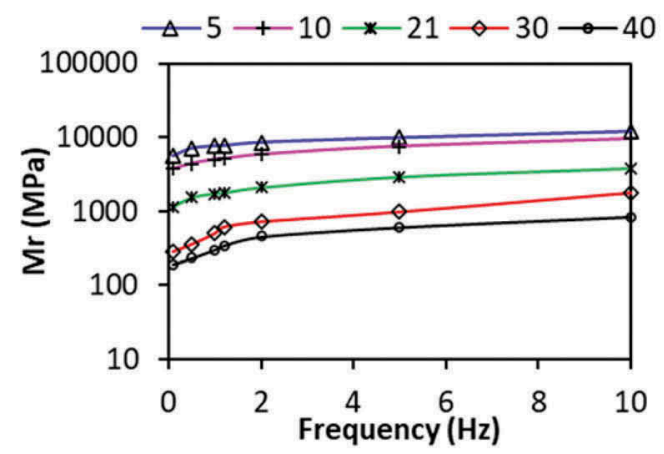

(a)

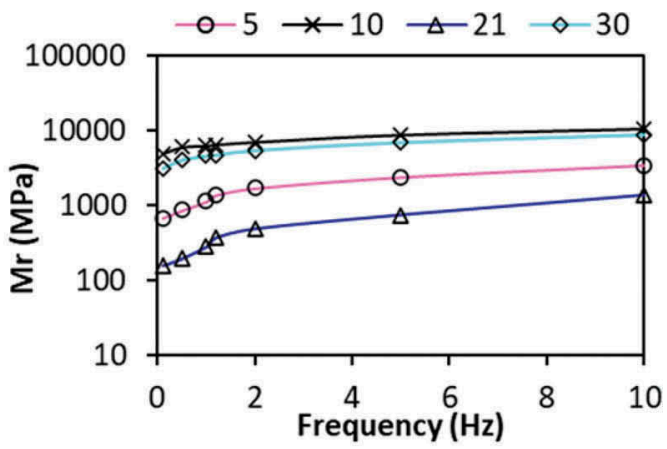

(b)

Figure 3. Resilient Modulus (Mr) test results (a) Ab11 (b) Agb11.
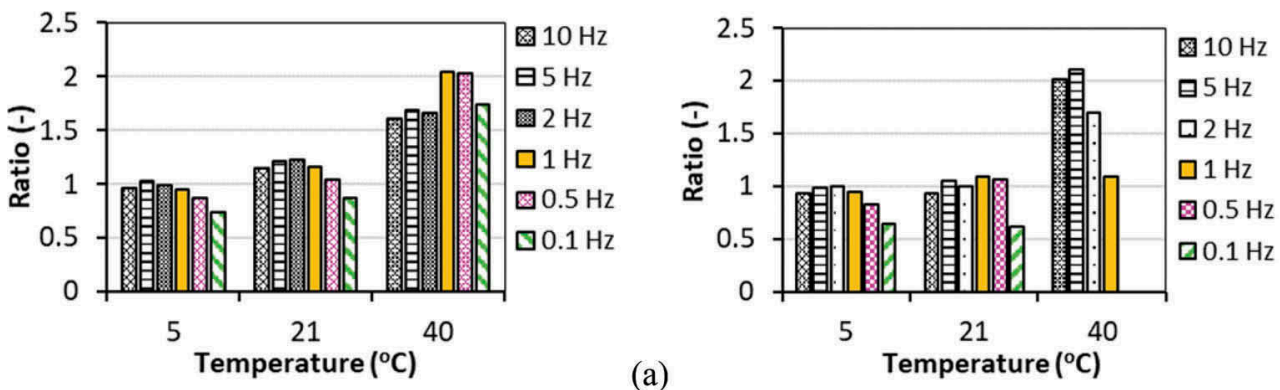

(a)

Figure 4. Dynamic to Resilient Modulus Ratio at same temperature and frequency (a) Ab11 (b) Agb11. 


\section{COMPARISON BETWEEN DYNAMIC AND RESILIENT MODULI}

\subsection{Master curve construction for $E^{*}$ and $M r$}

The test data are shifted horizontally (along the logarithmic time or frequency axis) to construct a master curve at a reference temperature. In this paper, two different models are used to develop a master curve for dynamic and resilient moduli. The first is the mathematical Sigmoid function (Equation 6) (Pellinen et al., 2002) and the second type is a rheological model referred to as the 2S2P1D model (Equation 7). The 2S2P1D model was developed at the DGCB laboratory of the ENTPE (Olard and Di Benedetto, 2003, Tiouajni et al., 2011). The model consists of 2 Springs, 2 Parabolic creep elements, and 1 Dashpot in the continuous spectrum.

$$
\log \left|\mathrm{E}^{*}\right|=\delta+\frac{(\alpha-\delta)}{1+\exp \left(\eta-\gamma \log \mathrm{R}_{\mathrm{R}}\right)}
$$

where $|E|$ - the dynamic modulus; $\delta, \alpha$ - the minimum and maximum logarithm dynamic modulus, respectively; $\eta, \gamma$ - shape factors; $f_{R}=f . \alpha_{T}$ - reduced frequency; $\alpha_{T}$ - timetemperature shift factor.

$$
\mathrm{E}_{22 \mathrm{~S} 2 \mathrm{P} 1 \mathrm{D}}(\omega)=\mathrm{E}_{00}+\frac{\mathrm{E}_{0}-\mathrm{E}_{00}}{1+\delta(\mathrm{i} \omega \tau)^{-\mathrm{k}}+(\mathrm{i} \omega \tau)^{-\mathrm{h}}+(\mathrm{i} \beta \omega \tau)^{-1}}
$$

Where $\omega$ - the angular frequency $(\omega=2 \pi \mathrm{f}) ; \delta, \mathrm{k}, \mathrm{h}-$ constants such that $0<\mathrm{k}<\mathrm{h}<1$;

$\mathrm{E}_{00}$ - static modulus $(\omega \rightarrow 0) ; \mathrm{E}_{0}$ - the glassy modulus $(\omega \rightarrow+\infty) ; \eta$ - the Newtonian viscosity of the dashpot $\left[\eta=\left(\begin{array}{ll}\mathrm{E}_{0} & \mathrm{E}_{00}\end{array}\right) \beta \tau\right] ; \beta$ - a constant that depends on the viscosity of the dashpot; $\tau$ - the characteristic time $\left[\tau=a T \tau_{0}\right]$ where $\tau_{0}$ is determined at a reference temperature.

The shift factors and master curves presented in this paper are all at $21^{\circ} \mathrm{C}$ reference temperature, and modeling constants are determined by nonlinear optimization using the solver function in Microsoft Excel. As shown in Figure 5 and Figure 6, both the sigmoid and the 2S2P1D models accurately fit a smooth dynamic modulus master curve for both mixtures (Ab11 and Agb11). However, the rheological 2S2P1D model has difficulty producing a smooth resilient modulus master curve. On the other hand, the sigmoid function has shown a good fit for the measured $\mathrm{Mr}$ data. The dynamic modulus master curve is generally bigger

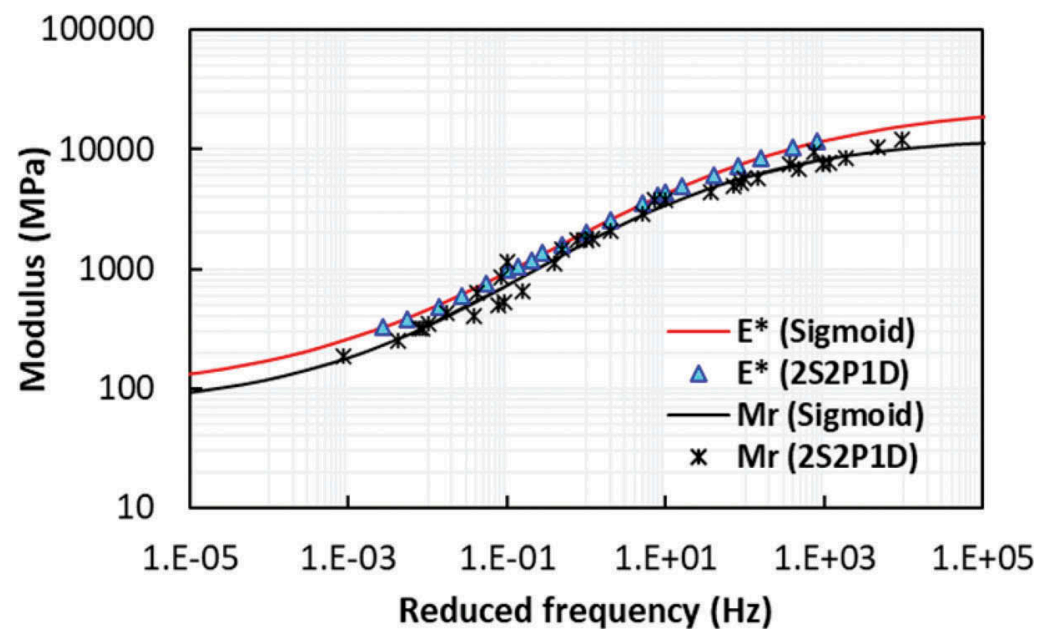

Figure 5. Dynamic modulus ( $\left.\mathrm{E}^{*}\right)$ and Resilient Modulus (Mr) Master Curves (Ab11). 
than the resilient modulus at the same temperature and frequency due to the rest period in the resilient modulus test (i.e., recovered strain is larger than strain amplitude in dynamic modulus) (Loulizi et al., 2006). However, this conclusion is not always the case. As shown in Figure 6, the $\mathrm{Mr}$ curve is above the $\mathrm{E}^{*}$ at low frequency (less $1 \mathrm{~Hz}$ ) and below the $\mathrm{E}^{*}$ curve at high frequencies for the Agb11 asphalt concrete. The corresponding time-temperature shift factors are shown in Figure 7.

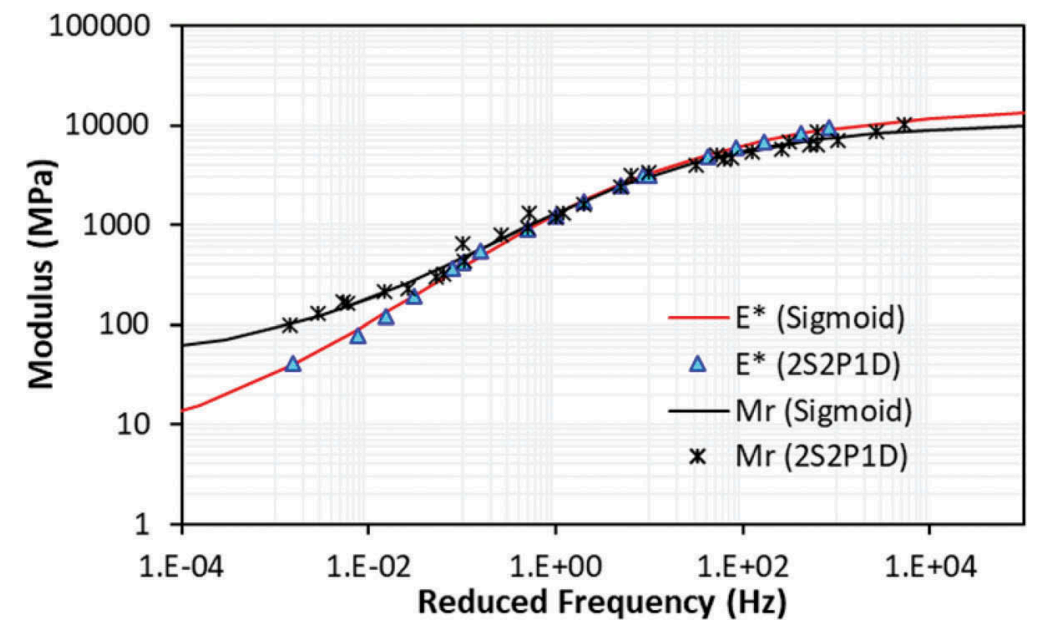

Figure 6. Dynamic modulus ( $\left.\mathrm{E}^{*}\right)$ and Resilient Modulus (Mr) Master Curves (Agb11).

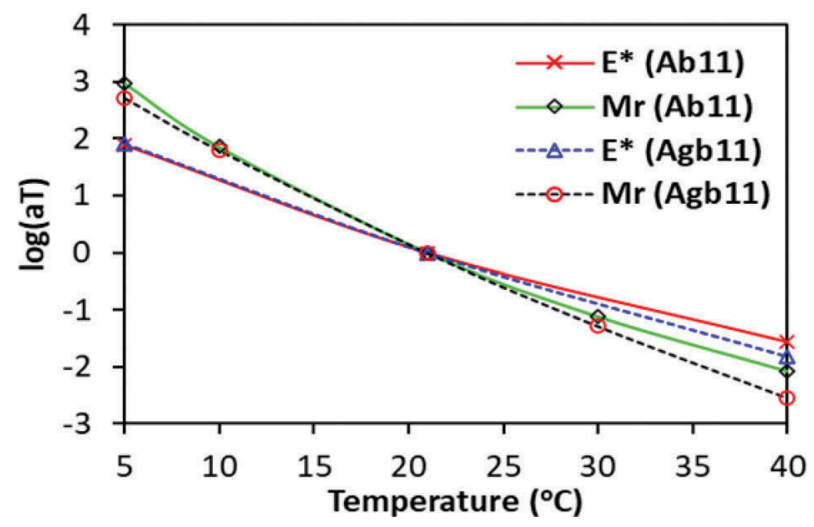

Figure 7. Temperature shift factors.

\subsection{Storage dynamic modulus ( $\left.E^{\prime}\right)$ vs. resilient modulus ( $\mathrm{Mr}$ )}

During the deformation of a viscoelastic body, part of the total work of deformation is dissipated as heat through viscous losses, but the remainder of the deformational energy is stored elastically (Tschoegl, 1989). The dissipated energy per unit volume $\left(\mathrm{J} / \mathrm{m}^{3}\right.$ per cycle) due to viscous effects is the loss modulus. The ratio of loss $\left(\Delta W=\pi \sigma_{0} \varepsilon_{0} \sin \varphi\right)$ to maximum stored ( $W=\frac{\sigma_{o} \varepsilon_{o}}{2}$ ) energy per cycle (also called specific loss) is given in Equation 8 . 


$$
\frac{\Delta \mathrm{W}}{\mathrm{W}}=\frac{\pi \sigma_{\mathrm{o}} \varepsilon_{\mathrm{o}} \sin \varphi}{\frac{\sigma_{0} \varepsilon_{0}}{2}}=2 \pi \sin \varphi
$$

Where $\sigma_{o}, \varepsilon_{o}, \varphi$ - stress amplitude, strain amplitude, and phase angle, respectively. Note that the specific loss is independent of the stress and strain amplitude.

The storage modulus $\left(\mathrm{E}^{\prime}\right)$ is the relevant and crucial quantity used to compute the timedomain viscoelastic properties (compliance and relaxation modulus) of asphalt concrete. As $\mathrm{Mr}$ is a time-domain test, it is imperative to compare the two moduli at similar conditions. The average ratios ( $\kappa=E^{\prime} / \mathrm{Mr}$ ) are found to be 1.12 and 0.84 for Ab11 and Agb11, respectively. Figure 8 (a and b) shows the $E^{\prime}$ and $M r$ master curves for both specimens, and Figure 9 presents the comparison. One can observe the changes in Figure 5 and Figure 6, and Figure 8. For the Ab11 mixture, $\mathrm{E}^{\prime}$ is very close to $\mathrm{Mr}$ at intermediate frequencies $(0.1$ to $10 \mathrm{~Hz}$ or the experimental window) while it barely changes from $\mathrm{E}^{*}$ at low and high reduced frequencies. For Agb11, the reduced frequency where $\mathrm{E}^{*}$ is equal to $\mathrm{Mr}$ (about $1.2 \mathrm{~Hz}$ ) has shifted to the right (about $10 \mathrm{~Hz}$ ) for $E^{\prime}$ and $M r$ curves.

The loss ratio of Ab11 and Agb11 is presented in Figure 10. A mixture with a softer binder (Agb11) has more energy loss than the stiffer mixture (Ab11), as expected. The maximum energy loss has occurred around the intermediate frequency. Furthermore, the bell-shaped energy loss curve indicates the thermo-rheological simplicity of the tested materials.

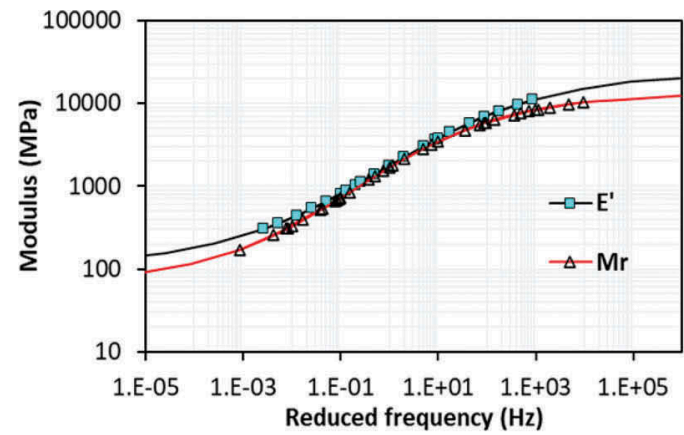

(a)

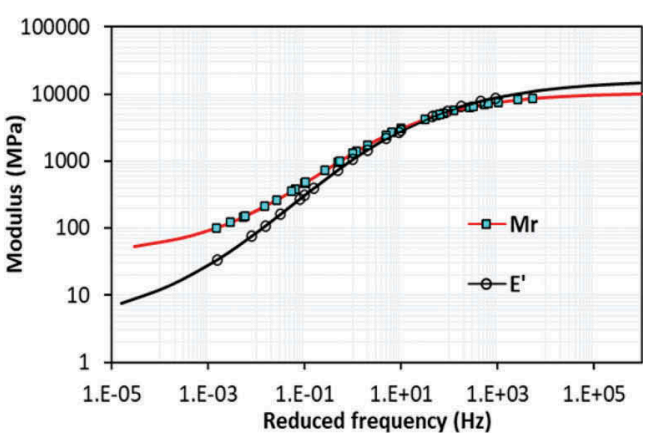

(b)

Figure 8. Master curves for $E^{\prime}$ and Mr using Sigmoid function (a) Ab11 (b) Agb11.

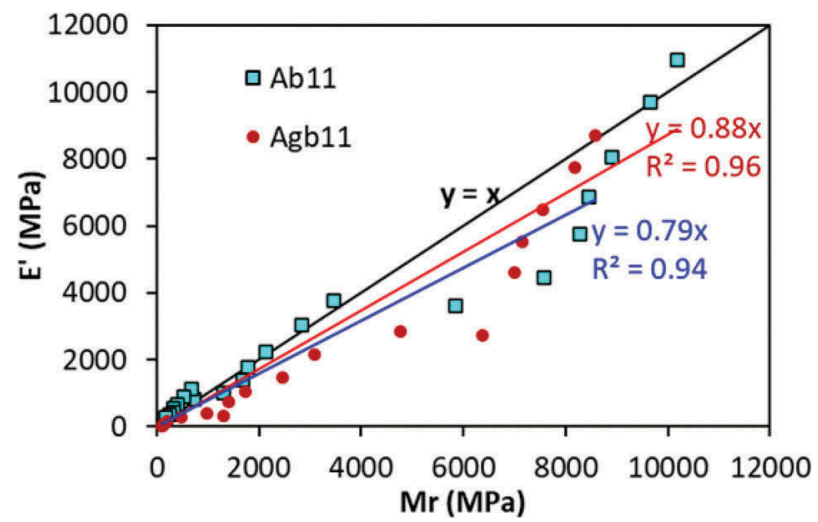

Figure 9. $E^{\prime}$ versus $\mathrm{Mr}$ for Ab11 and Agb11. 


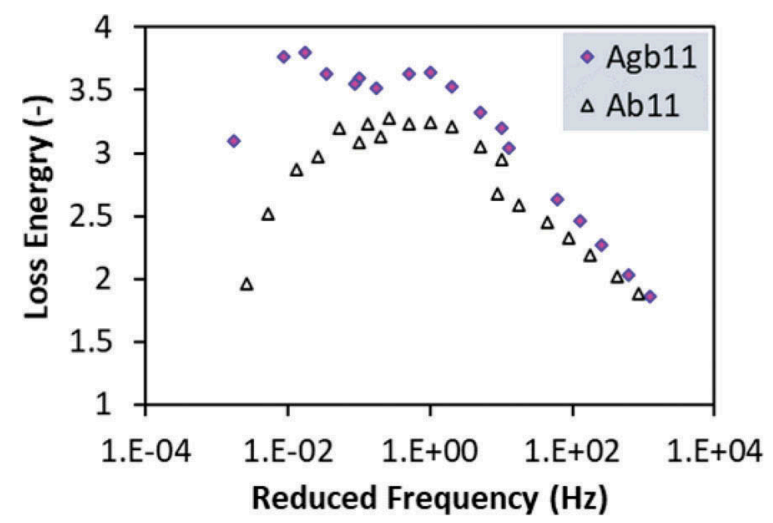

Figure 10. Energy loss for Ab11 and Agb11 mixtures.

\subsection{Relaxation modulus (E(t)) vs. resilient modulus ( $\mathrm{Mr}$ )}

Although the frequency domain dynamic modulus data can give sufficient information about asphalt concrete's viscoelastic properties, the time domain relaxation modulus and creep compliance are usually used in performance prediction. The generalized Maxwell model (GM) in parallel is used to obtain relaxation modulus, $\mathrm{E}(\mathrm{t})$. The one-dimensional $\mathrm{E}(\mathrm{t})$ a takes the following Prony form.

$$
E(t)=E_{\infty}+\sum_{m=1}^{M} E_{m}\left(\mathrm{e}^{\left(-t / \rho_{m}\right)}\right)
$$

Where $E_{\infty}$ - Long-term (equilibrium) modulus; $E_{m}$ - components of the relaxation modulus; $\rho_{m}$ - components of relaxation time; and $\mathbf{M}$ - the total number of the Maxwell elements (one Maxwell element is composed of one elastic spring and one viscous dashpot connected in series).

The Prony coefficients are determined by the least-squares method from dynamic storage modulus $\left(\mathrm{E}^{\prime}\right)$. A good fit is obtained by optimizing eight Prony coefficients $\left(E_{m}\right.$ and $\left.\rho_{\mathrm{m}}\right)$. As can be seen from Figure 5, Figure 8, and Figure 11, the Mr curve is less than the $\mathrm{E}^{\prime}$ and $\mathrm{E}(\mathrm{t})$ master curves. The $\mathrm{E}^{\prime}$ vs. $\mathrm{Mr}$ and $\mathrm{E}(\mathrm{t})$ vs. Mr curves have the same goodness of fit except the $\mathrm{x}$-axis domain is frequency and time, respectively.

Finally, although IDT is more of a quality control test, vital physical properties can be extracted. The virtues of IDT (such as simplicity, economy, repeatability, versatility) are the advantages for industrial applications over the companion dynamic modulus test. $\mathrm{Mr}$ alone cannot explain the viscoelastic property of asphalt concrete. Therefore, it is envisaged that advanced analyses should be undertaken by correlating with $\mathrm{E}^{*}$ to deduce the fundamental properties (such as relaxation and compliance moduli) from already collected and stored IDT test data.

\section{CONCLUSION}

This paper presents comparative analyses between dynamic modulus $\left(\mathrm{E}^{*}\right)$ and Indirect Tensile Resilient modulus (Mr) in linear viscoelastic range. Two different asphalt mixes are used for the investigation. The time-temperature superposition principle is used to construct $\mathrm{E}^{*}$ and Mr master curves using sigmoid and 2S2P1D models. Based on the analyses and observations presented in this study, the following conclusions can be drawn. 


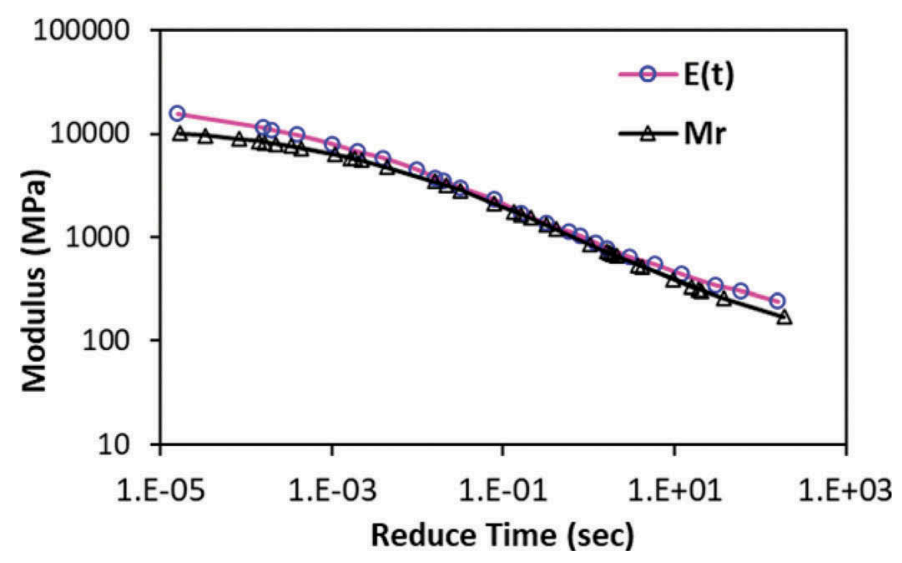

Figure 11. Master curves for $E(t)$ and $\mathrm{Mr}$ for $\mathrm{Ab} 11$.

- The thermo-rheological simplicity of two asphalt concrete mixtures (Ab11 and Agb11) is investigated using the time-temperature superposition principle.

- An S-shaped master curve is developed using the sigmoid and the 2S2P1D functions for both resilient and dynamic moduli test data. Unlike the sigmoid function, the rheological 2S2P1D model showed some waviness to reflect a smooth Mr master curve. This could be related to the model's inherent sinusoidal nature and is suitable for the harmonic stressstrain evolution.

- Comparison between the three quantities (i.e., $\mathrm{E}^{*}, \mathrm{E}^{\prime}$, and $\mathrm{Mr}$ ) is performed at the same temperature and frequency. The average ratios between $\mathrm{E}^{*}$ and $\mathrm{Mr}$ are found to be 1.27 for Ab11 and 1.12 for Agb11 mixes. Similarly, reduced average ratios of 1.12 and 0.84 are found between $\mathrm{E}^{\prime}$ and $\mathrm{Mr}$ due to the deduction loss modulus. It is recognized that the ratios of $\mathrm{E}^{*}$ and $\mathrm{Mr}$ is dependent on several factors like mixe type, temperature, frequency, etc.

- The time-domain relaxation modulus $(\mathrm{E}(\mathrm{t}))$ master curve is constructed using the Prony method. Almost identical goodness of fit $(96 \%)$ is found like the $E^{\prime}$ master curve. Generally, the comparison of time-domain quantities of $\mathrm{E}^{*}$ with $\mathrm{Mr}$ is reasonable and practical.

- In addition, a material database is obtained for Ab11 and Agb11 mixtures at wide frequencies and temperatures that can be utilized for the Norwegian pavement management system.

- This work is a preliminary study comparing $\mathrm{Mr}$ with $\mathrm{E}^{*}$ for asphalt concrete by developing master curves in both the time and frequency domain. More advance vertical shifting models are needed with more datasets.

\section{REFERENCES}

Bennert, T., Haas, E. \& Wass, E. 2018. Indirect Tensile Test (IDT) to Determine Asphalt Mixture Performance Indicators During Quality Control Testing In New Jersey. Transportation Research Record: Journal Of The Transportation Research Board, 2672, 394403.

Gayte, P., Di Benedetto, H., Sauzéat, C. \& Nguyen, Q. T. 2016. Influence Of Transient Effects For Analysis Of Complex Modulus Tests On Bituminous Mixtures. Road Materials And Pavement Design, 17, 271-289.

Lacroix, A., Khandan, A. A. M. \& Kim, Y. R. 2007. Predicting The Resilient Modulus Of Asphalt Concrete From The Dynamic Modulus. Transportation Research Record: Journal Of The Transportation Research Board, 2001, 132-140. 
Levenberg, E. \& Uzan, J. 2004. Triaxial Small-Strain Viscoelastic-Viscoplastic Modeling Of Asphalt Aggregate Mixes. Mechanics Of Time-Dependent Materials, 8, 365-384.

Loulizi, A., Flintsch, G. W., Al-Qadi, I. L. \& Mokarem, D. 2006. Comparing Resilient Modulus And Dynamic Modulus Of Hot-Mix Asphalt As Material Properties For Flexible Pavement Design. Transportation Research Record: Journal Of The Transportation Research Board, 1970, 161-170.

Nguyen, M. L., Sauzéat, C., Di Benedetto, H. \& Tapsoba, N. 2013. Validation Of The Time-Temperature Superposition Principle For Crack Propagation In Bituminous Mixtures. Materials And Structures, 46, 1075-1087.

Olard, F. \& Di Benedetto, H. 2003. General "2S2P1D” Model And Relation Between The Linear Viscoelastic Behaviours Of Bituminous Binders And Mixes. Road Materials And Pavement Design, 4, 185-224.

Pellinen, T. K., Witczak, M. W. \& Bonaquist, R. F. Asphalt Mix Master Curve Construction Using Sigmoidal Fitting Function With Non-Linear Least Squares Optimization. Recent Advances In Materials Characterization And Modeling Of Pavement Systems, 2002. 83-101.

Ping, W. V. \& Xiao, Y. 2008. Empirical Correlation Of Indirect Tension Resilient Modulus And Complex Modulus Test Results For Asphalt Concrete Mixtures. Road Materials And Pavement Design, 9, 177-200.

Schwartz, C. W., Gibson, N. \& Schapery, R. A. 2002. Time-Temperature Superposition For Asphalt Concrete At Large Compressive Strains. Transportation Research Record: Journal Of The Transportation Research Board, 1789, 101-112.

Tiouajni, S., Di Benedetto, H., Sauzéat, C. \& Pouget, S. 2011. Approximation Of Linear Viscoelastic Model In The 3 Dimensional Case With Mechanical Analogues Of Finite Size. Road Materials And Pavement Design, 12, 897-930.

Tschoegl, N. W. 1989. Energy Storage And Dissipation In A Linear Viscoelastic Material. In: TSCHOEGL, N. W. ( Ed. ) The Phenomenological Theory Of Linear Viscoelastic Behavior: An Introduction. Berlin, Heidelberg: Springer Berlin Heidelberg.

Williams, M. L., Landel, R. F. \& Ferry, J. D. 1955. The Temperature Dependence Of Relaxation Mechanisms In Amorphous Polymers And Other Glass-Forming Liquids. Journal Of The American Chemical Society, 77, 3701-3707.

Yun, T., Underwood, B. S. \& Kim, Y. R. 2010. Time-Temperature Superposition For HMA With Growing Damage And Permanent Strain In Confined Tension And Compression. Journal Of Materials In Civil Engineering, 22, 415-422.

Yusoff, N. I. M., Chailleux, E. \& Airey, G. D. 2011. A Comparative Study Of The Influence Of Shift Factor Equations On Master Curve Construction. International Journal Of Pavement Research And Technology, 4, P. 324-336.

Zhao, Y. \& Richard Kim, Y. 2003. Time-Temperature Superposition For Asphalt Mixtures With Growing Damage And Permanent Deformation In Compression. Transportation Research Record: Journal Of The Transportation Research Board, 1832, 161-172. 